\title{
Compliance with Malaria Rapid Diagnostic Test Results and Correlates among Clinicians in Uyo, Akwa Ibom State, Nigeria: 2018
}

\author{
Goodwill B. Effah1 ${ }^{(1)}$, Bernadine Ekpenyong1, Gbadebo Babatunde², Ikeoluwapo 0. Ajayi2, \\ David Dairo $^{2}$ \\ ${ }^{1}$ Epidemiology and Medical Statistics Unit, Department of Public Health, University of Calabar, Calabar, Nigeria \\ ${ }^{2}$ Department of Epidemiology and Medical Statistics, University of Ibadan, Ibadan, Nigeria \\ Email: geffah69@yahoo.com
}

How to cite this paper: Effah, G.B., Ekpenyong, B., Babatunde, G., Ajayi, I.O. and Dairo, D. (2019) Compliance with Malaria Rapid Diagnostic Test Results and Correlates among Clinicians in Uyo, Akwa Ibom State, Nigeria: 2018. Open Journal of Epidemiology, 9, 259-288.

https://doi.org/10.4236/ojepi.2019.94020

Received: May 27, 2019

Accepted: September 26, 2019

Published: September 29, 2019

Copyright $\odot 2019$ by author(s) and Scientific Research Publishing Inc. This work is licensed under the Creative Commons Attribution International License (CC BY 4.0).

http://creativecommons.org/licenses/by/4.0/

cc) (i) Open Access

\begin{abstract}
Introduction: In sub-Saharan Africa, $80 \%$ to $85 \%$ of RDT negative febrile patients, seen in outpatient clinics, were given anti-malarial medicines. Previous studies recommended investigating determinants of "compliance with RDT' results" in specific cadre and setting, as intervention is most effective when context specific. Compliance with malaria RDT results and correlates among clinicians in Uyo was determined. Methods: A cross-sectional study of clinicians selected using stratified sampling. Data were collected using self-administered, semi-structured questionnaire on socio-demographics, facility audit of RDT supplies, knowledge, perception and practice of clinicians. Outcome variable of interest was whether or not clinicians self-reported compliance with RDT results. Exposure variables of interest were whether or not clinicians received RDT training; received supportive supervision for malaria RDT; had positive perception of RDT usefulness; had good knowledge of RDT use (scores of $\geq 75 \%$ in questions testing for knowledge); had readily available treatment guidelines; had diagnostic capacity for other common febrile illness; experienced patient overload; experienced stock-out of supplies; work in the private/public sector. Descriptive, bivariate and multivariate analyses were conducted. Results: Mean age of the clinicians was 33.0 years \pm (6.0 SD). Of the total clinicians, 31.1\% were female; $66.0 \%$ received RDT training; $36.4 \%$ had supportive supervision; $43.3 \%$ exhibited good knowledge of RDT use; $45.3 \%$ had positive perception of RDT usefulness and $41.7 \%$ relied on presumptive diagnosis. Compliances with RDT negative and positive results were $66.4 \%$ and $83.4 \%$ respectively. Compliance with RDT negative result was more in clinicians with good knowledge of RDT use $(\mathrm{aOR}=25.0$; $95 \% \mathrm{CI}=2.92-213.52)$. Compliance with RDT positive result was more in
\end{abstract}


clinicians with good knowledge of RDT use (aOR $=10.0 ; 95 \% \mathrm{CI}=2.70$ 18.72), positive perception of RDT usefulness ( $\mathrm{aOR}=10.2 ; 95 \% \mathrm{CI}=3.50$ 29.63) and in health facilities in the public sector $(\mathrm{aOR}=5.0 ; 95 \% \mathrm{CI}=2.00$ -

11.11). Training on RDT use was not significantly associated with compliance with $\mathrm{RDT}$ negative $(\mathrm{aOR}=1.25 ; 95 \% \mathrm{CI}=0.63-2.44)$ nor positive result ( $\mathrm{aOR}=2.0 ; 95 \% \mathrm{CI}=0.63-5.00)$. Conclusions: Compliance was higher with RDT positive result; more in the public sector; and in clinicians with good knowledge of RDT use. Efforts to improve compliance should focus on RDT negative results; clinicians with poor knowledge of RDT use and negative perception of RDT usefulness; and those in the private sector. However further research involving explicit (analytic) study of compliance with RDT results is recommended.

\section{Keywords}

Compliance, Knowledge, Perception, Practice, Malaria, RDT Results

\section{Introduction}

\subsection{Background}

Clinicians' compliance with treatment guidelines is one of the components of effective case management of malaria. The other components include prompt access to treatment and diagnosis as well as patients' adherence to prescriptions (World Health Organization) [1]. In 2010 the WHO recommended parasitological confirmation of malaria infection before commencing Artemisinin combination therapy (ACT) as part of the treatment guidelines [2].

Clinical management of malaria without parasitological confirmation may lead to over-diagnosis of malaria; missed diagnosis of malaria; under-diagnosis of non-Malaria febrile illness; irrational use of resources and unnecessary exposure to adverse drug reaction. The other sequels of presumptive diagnosis of malaria include: over prescription of anti-malaria and thus, drug wastage; development of drug resistance as well as neglect of the underlying causes of the non-malaria febrile illnesses [3].

Microscopy for confirmation of malaria is expensive, time-consuming and labor-intensive. These shortcomings partly informed the development of rapid diagnostic test [4]. Use of Rapid Diagnostic Test (RDT) for confirmation of malaria is suitable for resource-limited settings. It is more suitable in peripheral areas where microscopy is not available [5].

For the purpose of this study "compliance" refers to "self-reported compliance" (i.e. clinicians reported treating patients according to malaria RDT result consistently, in the two weeks prior to survey). Two weeks were adopted based on the study conducted by Pulford et al. [6]. He assumed that clinician self-report is a reliable proxy indicator of compliance, more accurate than patient self-report [7]. Also, clinicians refer to Medical Doctors. 


\subsection{Statement of the Problem}

Malaria still remains a leading public health problem in sub-Saharan Africa even though the prevalence has reduced because of the ongoing intensified efforts at control [8]. Malaria accounts for $60 \%$ of out-patient attendance and $30 \%$ of hospital admissions in Nigeria. In malaria endemic countries in sub-Saharan Africa, clinicians still prescribe anti-malaria drug to clients with Malaria RDT negative results: $80 \%$ to $85 \%$ of $\mathrm{RDT}$ negative febrile patients seen by clinicians are treated for malaria [9]. Compliance with malaria RDT result was found to be generally poor, especially when the result is negative [10].

In a study conducted in Nigeria, compliance with RDT negative and positive result was $25.9 \%$ and $100 \%$ respectively [11]. Another study conducted in Zambia revealed a compliance rate of $31.4 \%$ and $93.9 \%$ for RDT negative and positive results respectively [12]. In Nigeria most of the illness treated in health centers is presumptive malaria [11]. Mokuolu and his associates revealed a non-compliance rate of $30.4 \%$ to malaria RDT negative results in private health facilities in Nigeria [13]. The following have been identified as determinants of compliance with RDT results: perception; attitudes and "feeling under pressure" from patients to prescribe irrespective of RDT result [14].

In Akwa Ibom State, malaria is responsible for over $70 \%$ of outpatient attendance. In 2016 about 246,362 confirmed uncomplicated malaria and 2863 severe malaria cases were reported by Health management information system (HMIS) in the.

\subsection{Justification}

Akwa Ibom is a malaria endemic State. Moreover, anecdotal evidence suggested that compliance with RDT result in Akwa Ibom State is low. Furthermore, there is paucity of data on compliance of clinicians with malaria RDT results in Uyo, Akwa Ibom State. Most of the data available on clinicians' compliance to RDT guidelines are from studies conducted outside Akwa Ibom State [15].

Moreover, previous studies recommend that it is essential to investigate factors contributing to "compliance to RDT results" in specific cadres and settings, as interventions are most effective if they are context-specific. Clinicians were chosen for the study out of all other cadres that provides malaria treatment because the prevalence of non-compliance is higher amongst the clinicians compared to the other cadre of health providers [16].

This study will identify the determinants of clinicians' compliance with malaria RDT results in Akwa Ibom State, and then provide recommendations taking into considerations the results and limitations of the study. It will inform developing an intervention programme tailored towards changing the perception of defaulting clinicians militating against strict compliance with malaria RDT results.

\subsection{Research Questions}

1) What is the proportion of clinicians' who comply with Malaria RDT results 
in Uyo, Akwa Ibom State?

2) What are the factors influencing clinicians' adherence to guideline on malaria RDT results?

3) What is the association between commonly known determinants and Clinician compliance with RDT results in Uyo, Akwa Ibom State?

4) Is there any association between the Healthcare sector and Clinician exhibiting compliance with malaria RDT results?

5) Is there any association between the socio-demographic factors and Clinician exhibiting compliance with malaria RDT results?

\subsection{General Objective}

To determine compliance with malaria RDT results and the associated factors among clinicians in Uyo, Akwa Ibom State.

\section{Specific Objectives}

1) To assess the level of knowledge of clinicians about malaria RDT use.

2) To determine clinicians perception about RDT usefulness in Uyo, Akwa Ibom State.

3) To determine compliance with malaria RDT result.

4) To determine malaria diagnosis practices among clinicians in Uyo, Akwa Ibom State.

5) To determine the factors associated with compliance with malaria RDT result.

\section{Methods}

\subsection{Study Area}

Akwa Ibom is located in the South-south geopolitical zone and is bordered on the East by Cross River State, on the West by Rivers State and Abia State, and on the South by the Atlantic Ocean and the southernmost part of Cross River State (Figure 1). The State capital is Uyo. The State is a predominantly public service state while the rural settlers are mainly farmers and fishermen. Akwa Ibom is weathered by the tropical monsoon. In tropical monsoon climate, March to November is suitable for malaria transmission because the precipitation is above 80 $\mathrm{mm}$, relative humidity above $60 \%$ and temperature between $18 \%$ and $32 \%$ [17].

The State health system comprises the public and the private sectors. The public sector comprises the tertiary, secondary and primary health centers. The tertiary and secondary health centers act as referral units while the primary health centers provide basic preventive, curative, promotive and rehabilitative care in rural settings. The private sector comprises the formal and informal private sectors. The formal private sector comprises the private not-for-profit (missionaries and NGO's) and the private for-profit organizations. The informal private sector comprises the patent medicine vendors and the traditional medicine providers. Uyo LGA has 86 registered health establishments. This is broken down as follows: University of Uyo Teaching Hospital (one); Ibom Specialist 


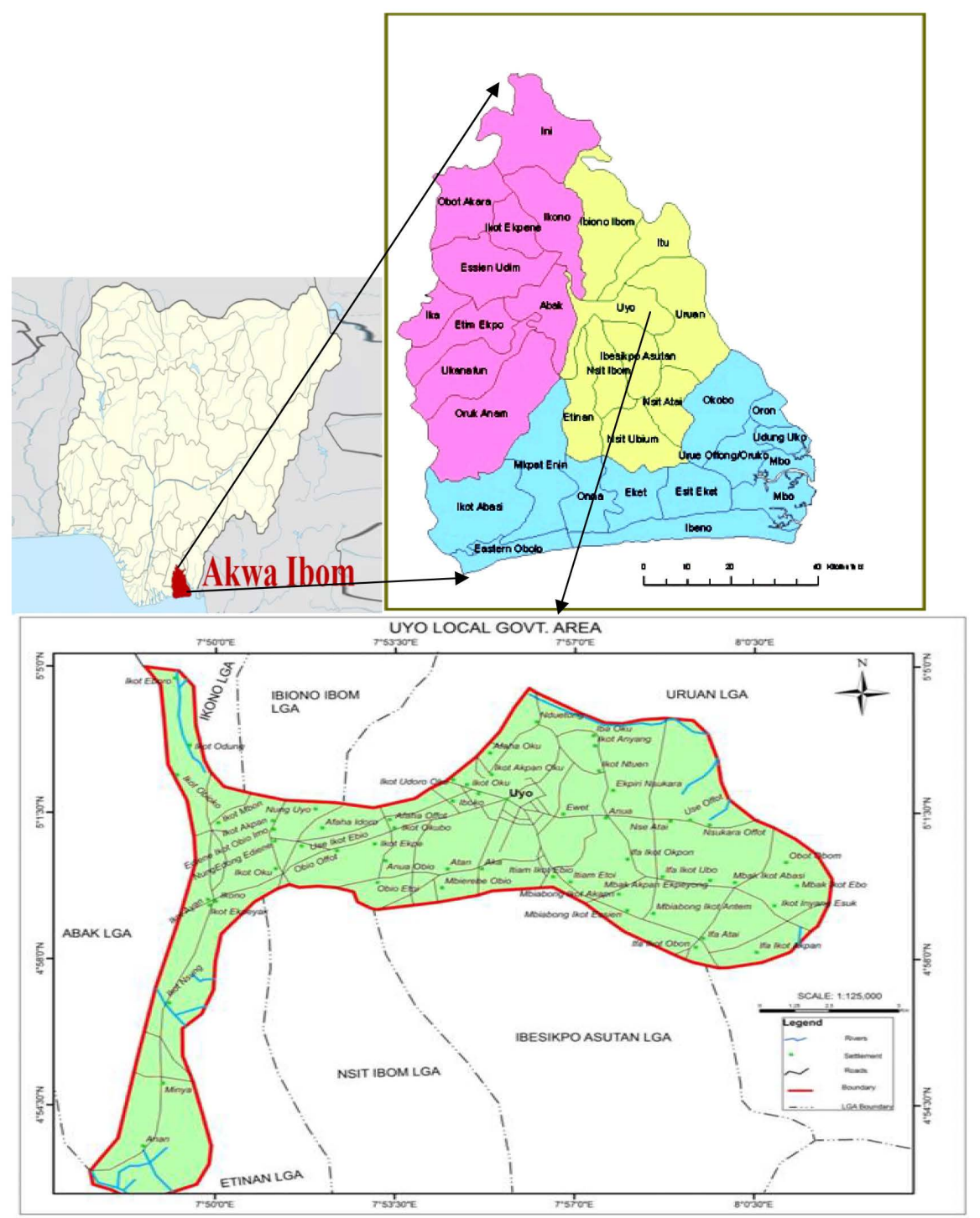

Figure 1. Map of Nigeria showing Uyo, Akwa Ibom State (source SMOH).

Hospital (one); Primary Health Centers (20); mission hospital (one) and Private Clinics (63). Out of the 887 medical doctors registered in Akwa Ibom State, 696 were practicing in Uyo LGA. The 696 Doctors mentioned above are distributed over University of Uyo Teaching Hospital; Saint Luke Hospital Anua, Uyo and the Private for profit organizations. Ibom Specialist Hospital was excluded from the study because the hospital was on indefinite strike throughout the period of the study.

As at 2006 Akwa Ibom was classified as an "orphaned" State because they were left out of the Global fund for malaria. The State started receiving World Bank assistance for malaria control in 2007. Akwa Ibom was added to the PMI supported (Presidents Malaria Initiatives) States in 2013. In 2017 the State Government established a parasite and vector sentinel sites in Uyo and Eket LGAs. There is a strong collaboration between the State and the National Malaria Elimination Program (NMEP); the Role Back Malaria partners; international and 
the Non-Governmental Organization (NGO). This partnership is an integrated effort to ensure continuous availability of malaria commodities (Artemisinin-based combination therapy (ACT), Sulfadoxine pyrimethamine (SPs), RDT-kits and LLINs) in all health facilities in the State.

There are private, state and federal government's radio and television service centers that provide social amenities, ensuring social integration of the citizens and dissemination of health and other information. They operate under the supervision of the ministry of information.

\subsection{Study Design}

A cross sectional study involving clinicians in public and private health care facilities was carried out. The study was conducted between November, 2017 and March, 2018 in Uyo, Akwa Ibom State.

\subsection{Study Population}

The study population included all clinicians saddled with the responsibility of malaria case management in public and private health facilities in Uyo. Clinicians responsible for malaria case-management in the selected health facilities and consulting on the day of interview were included in the study.

\subsection{Sample Size}

\subsubsection{Minimum Sample Size}

The sample size formula used is that of sample size for proportion designed for descriptive cross sectional study with qualitative outcome variable [18]

$$
n=\frac{Z_{1-\alpha / 2}^{2} p(1-p)}{d^{2}}=\frac{1.96^{2} \times 0.696 \times 0.304}{0.05^{2}}=325
$$

Key

$n=$ minimum sample size $=325$.

$p=$ proportion of clinicians' compliant with malaria RDT negative result from previous studies in the private sector Nigeria $=69.6 \%[13]$.

$q=1-p=1-0.696=0.304$.

$Z_{\alpha}=$ risk of type one error $=1.96$ ( 2 sided at $5 \%$ level of significance).

$d=$ desired precision $=5 \%$.

\subsubsection{Finite Population Correction Factor Formula}

The minimum sample size of 325 was greater than $5 \%$ of the population size (Doctors registered in Uyo in Akwa Ibom State). Therefore adjustment was made for finite population correction:

$$
n_{a}=\frac{n_{r}}{1+\frac{n_{r}-1}{N}}=\frac{325}{1+(325-1) / 696}=222
$$

Key

$n_{a}=$ adjusted sample size.

$n_{r}=$ the original required minimum sample size. 
$N=$ population size (Number of registered medical doctors in Uyo LGA).

\subsubsection{Non-Response Rate}

$$
q=\frac{1}{1-f}=\frac{1}{1-0.1}=1.1111
$$

\section{Key}

$q=$ adjustment for non-response rate.

$f=$ estimated non-response rate $=10 \%$ (this percentage was used because of the following reasons: the mode of distribution of the questionnaires was in-person and the target population constitutes an external audience. These factors tend to lower response rate).

Minimum sample size adjusted for non-response $=1.1111 \times 222=247$.

\subsection{Sampling Technique}

The health facilities in the LGA were initially stratified into private for-profit (PFP), private not-for-profit (PNFP) and public (Figure 2). A list of clinicians in each health facility was prepared and merged to form list per stratum. This gave us 161 clinicians in PFP, 56 in PNFP and 479 in public hospital. Probability proportional to size was (PPS) was used to allocate the sample size to each stratum. Table of random number listing (RNL) was generated using excel to select clinicians from each stratum. Clinician who could not be reached was replaced by another number generated by RNL.

\subsection{Data Collection}

\subsubsection{Data Collection Instrument}

Data was collected by pre-tested self-administered semi-structured questionnaire. The questionnaire used for the study was adapted from those used in a previous study conducted in Nigeria [13]. The questionnaire had sections on socio-demographics; facility audit of infrastructure and supplies needed for parasitological confirmation of malaria; perception about RDT usefulness; knowledge about RDT use and diagnostic practice of clinicians.

\subsubsection{Data Collection Procedure}

Training sessions were conducted for research assistants prior to pre-test. Pre-test was conducted in General hospital, Abak LGA. Convenient sampling was done for the pre-test. Eight clinicians were selected and issued self-administered questionnaire. Their phone numbers were collected. Phone was used to contact them; retrieve the questionnaire; clarify issues related to the responses they made and ensure completeness of the fields. Face validity was done.

Health facility records (clinic registers, patient's folders and laboratory registers) were also reviewed to validate the responses of the clinicians on compliance status. To determine the number of folders to select, consulting room registers were used to get the unique identifiers (Hospital number) of patients treated for malaria by each participating clinician, two weeks prior to this survey. Two 


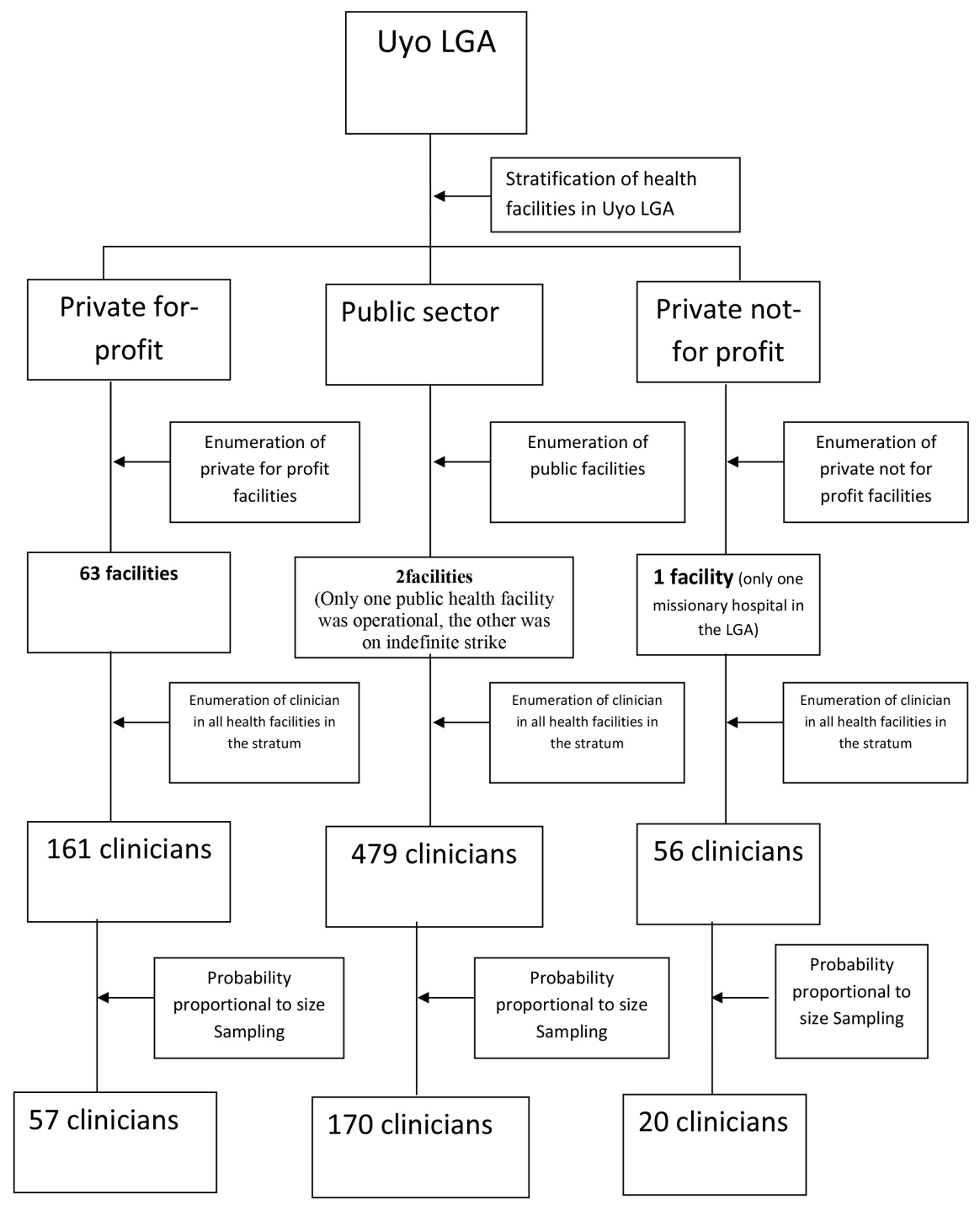

Figure 2. Flow chart of recruitment of respondents (clinicians).

weeks was adopted based on the study conducted by Pulford et al. [6]. These unique identifiers were then used to trace patient's folder. These folders were reviewed to establish whether prescriptions were issued prior to the availability of parasitological results or after; whether malaria RDT results influenced these prescriptions; and whether respondents treated patients according to malaria $\mathrm{RDT}$ result, consistently, in the two weeks prior to survey. Data abstraction from the folders was done by the data abstraction form adapted from Ayin et al. 2015 (Refer to supporting file, Appendix).

\subsubsection{Measurement of Variables}

The variables under study were classified into four groups for the purpose of data analysis: 1) outcome of interest; 2) exposures/explanatory variables of interest; 3) potential confounders and effect modifiers and finally 4) variables for sub-group analysis. Data analysis was done using classic analysis and dashboard 
of Epi-info.2.7.2. The primary outcome variable is the proportion of clinician compliant with RDT results in Akwa Ibom State.

Explanatory variables of interest include whether or not the clinicians received $\mathrm{RDT}$ training; received supportive supervision for malaria RDT; had positive perception of RDT usefulness; had good knowledge about RDT use.

Variables for sub-group analysis included these independent variables which may vary significantly among sub-groups of the population examples: 1) sex of clinician; 2) age group of clinician, 3) years of experience of clinician.

The level of knowledge of clinicians was determined by the number of correct choice made out of the 20 objective questions designed to test Knowledge about RDT use. Scoring 15/20 (75\%) and above denotes good knowledge. If less than $75 \%$ of these questions were answered correctly, the respondent was classified as having poor knowledge.

For questions testing for perception, Likert-type scale responses were required. The section of the questionnaire on perception has 6 questions (items). Each question has 5 options (categories): strongly disagree, disagree, undecided, agree and strongly agree. Each Likert scale category (option) was assigned a numerical value. This value ranges from 1 - 5, depending on whether the perception was a positive perception of the issue/event in question (scoring 4 and above denotes positive perception; while below 4 denotes negative perception). Next, the Likert scale items (question.) were combined to form a composite (survey scale) item (i.e. the 6 Likert scale items were combine to form one survey scale item). Each survey scale category now has a numerical value corresponding to the sum total of the related Likert scale categories (options). These values now range from 6 - 30, since there were six questions testing for perception. For the Likert scale categories numerical values of 4 and above reflects positive perception; values less than 4 reflects negative perception. For survey scale categories, numerical values of 24 and above reflects overall positive perception. Values less than 24 reflects overall negative perception.

\subsection{Data Analysis}

Data collected were entered into the computer using Epi-info 2.7.2. Data were cleaned by checking for duplicate records, miscoded, missing, and out-of-range values. Next, consistency and logic checks were conducted.

Univariate analysis of demographic data was conducted. Frequency distribution of relevant categorical data was computed to generate count and percent, reflecting the current malaria RDT diagnosis practice in Uyo.

Bivariate analysis was done by comparing the independent variables to the outcome variable of interest (compliance status of clinicians). Chi-square or fisher exact test was conducted depending on the expected frequency per cell. Chi-square or Fischer exact was used to test the association between the independent variables and Clinician' compliance status with RDT results at 5\% level 
of significance.

For perception, initial analysis of the Likert-type scale response was done by conducting a frequency distribution of the responses. Further analysis of the Likert-type-scale responses was made possible by converting the data from ordinal to interval data (i.e. coding the data). Multivariate logistic regression was conducted to determine independent variables associated with the outcome and to rule out confounders. Adjusted odd ratios and their $95 \%$ confidence interval were reported.

Responses to open ended questions were coded; grouped into themes and frequency table created.

\subsection{Ethical Approval and Consent to Participate}

Ethical approval for this study was obtained from the Akwa Ibom State Ethical Review Committee (Reference number-MH/PRS/99/Vol.IV/162; Date-15/01/2018). Full disclosure of the intent of the investigation was made to each participant to ensure adequate comprehension before written informed consent was obtained. Respondents were assured of the strict confidentiality of the information they provided. Personal identifier that may link participants was not used during the interview and analysis.

\section{Results}

\subsection{Demographic Characteristics of the Respondents}

A total of 247 clinicians participated in the study. Seventy seven $(31.17 \%)$ were females. The mean age of the respondents was 33 years $\pm 6 \mathrm{SD}$. The other relevant demographics of the respondents are presented in Table 1.

\subsection{Knowledge of Respondents about Malaria RDT Use}

A total of 107 (43.3\%) respondents had good knowledge about RDT use: 67 (39.4\%) from the public sector and $40(51.9 \%)$ from the private sector. Eighty eight (51.5\%) respondents from the public sector and 44 (57.9\%) respondents from the private sector stated correctly that improper handling of RDT kit may influence performance of the test. Seventy (40.9\%) clinicians in the public sector and $42(55.3 \%)$ in the private sector stated correctly that provision of management algorithm for malaria RDT negative result in consulting rooms will make RDT to be carried out correctly. Eighty five (49.7\%) clinicians from the public sector and 43 (56.6\%) clinicians from the private sector stated correctly that inappropriate storage of RDT kit may affect performance of the test. Sixty seven (39.2\%) clinicians from the public sector and $36(47.4 \%)$ clinicians from the private sector stated correctly that observer error when reading the result may influence performance of the test. Please refer to Table 2 for other responses to questions testing for knowledge.

\subsection{Perception of RDT Usefulness}

A total of $112(45.3 \%)$ respondents had positive perception of RDT usefulness: 
Table 1. Demographic and training characteristics of clinicians in Uyo: $2018(n=247)$.

\begin{tabular}{|c|c|c|}
\hline Descriptive Variable & Total & $\%$ \\
\hline \multicolumn{3}{|l|}{ Age group (years) } \\
\hline$<25$ & 13 & 5.3 \\
\hline $25-34$ & 140 & 56.7 \\
\hline $35+$ & 94 & 38.1 \\
\hline \multicolumn{3}{|l|}{ Sex } \\
\hline Male & 170 & 68.8 \\
\hline Female & 77 & 31.2 \\
\hline \multicolumn{3}{|l|}{ Marital status } \\
\hline Married & 216 & 87.4 \\
\hline Single & 31 & 12.6 \\
\hline \multicolumn{3}{|c|}{ Level of medical education } \\
\hline Graduate & 208 & 84.2 \\
\hline Post-graduate & 39 & 15.9 \\
\hline \multicolumn{3}{|l|}{ Work experience in years } \\
\hline $1-5$ & 139 & 56.3 \\
\hline $6-10$ & 77 & 31.2 \\
\hline $11-15$ & 22 & 8.9 \\
\hline $16-20$ & 8 & 3.2 \\
\hline $21-25$ & 1 & 0.1 \\
\hline \multicolumn{3}{|c|}{ Number who received RDT training* } \\
\hline Private sector & $57^{*}$ & $74.0^{*}$ \\
\hline Public sector & $114^{*}$ & $67.1^{*}$ \\
\hline \multicolumn{3}{|l|}{ Received RDT training } \\
\hline No & 76 & 30.8 \\
\hline Yes & 171 & 69.2 \\
\hline \multicolumn{3}{|c|}{ Received RDT supportive supervision } \\
\hline No & 157 & 63.6 \\
\hline Yes & 90 & 36.4 \\
\hline \multicolumn{3}{|l|}{ Facility type } \\
\hline Public & 170 & 68.8 \\
\hline Private & 77 & 31.2 \\
\hline \multicolumn{3}{|c|}{ The most recent RDT training } \\
\hline$>$ lyear & 52 & 21.1 \\
\hline$\leq$ lyear & 117 & 47.4 \\
\hline \multicolumn{3}{|c|}{ The most recent supportive supervision } \\
\hline$>1$ year & 48 & 19.4 \\
\hline$\leq 1$ year & 41 & 16.6 \\
\hline
\end{tabular}

*The denominator for the number of clinicians that received RDT training per sector is $\mathrm{n}=70$ for private sector; $\mathrm{n}=170$ for public sector. 
Table 2. Proportion of clinicians who responded correctly to selected questions testing for knowledge of RDT use in Uyo, Nigeria: 2018 ( $\mathrm{n}=247)$.

WHO recommends parasitological confirmation of malaria before commencing ACT (TRUE or FALSE)

Public sector

Private sector

Strict adherence to RDT results reduces over-treatment and drug wastage (TRUE or FALSE)

Public sector

$48(28.2 \%)$

Private sector

$37(48.1 \%)$

Strict adherence to RDT result has a positive effect on the health outcome of the patient (TRUE or FALSE)

Public sector

Private sector

performing a repeat test when RDT is negative renders the test result more useful (TRUE or FALSE)

Public sector

Private sector

$40(52.1 \%)$

RDT confirmation of malaria before treatment is cost effective relative to presumptive treatment (TRUE or FALSE)

Public sector $146(86.0 \%)$

Private sector $69(89.6 \%)$

Malaria RDT results are best read 15-20 minutes after the test (TRUE or FALSE)

Public sector

Private sector

performance of malaria RDT may be influenced by parasite density in the sampled blood (TRUE or FALSE)

Public sector

$87(50.9 \%)$

Private sector $52(68.4 \%)$

70 (41.2\%) from the public sector and 42 (54.5\%) from the private sector. Eighty three $(48.8 \%)$ respondents in the public health facilities perceived that RDT is reliable for parasitological confirmation of malaria compared to 41 (53.3\%) in the private health facility. Seventy seven $(45.3 \%)$ respondents in the public health facilities trusted their clinical judgment and past experience more than RDT result in confirming malaria infection compared to 38 (49.4\%) in private health facilities. The reasons given for trusting presumptive diagnosis more than RDT result ranges from the fact that they were well trained to make clinical diagnosis, $3.2 \%(\mathrm{n}=8)$ to the fact that they have a high clinical acumen, $10.5 \%(\mathrm{n}$ $=26)$. Other reasons are presented in Table 3 . Eighty eight $(51.2 \%)$ respondents in the public health facilities perceived that RDT is useful in parasitological 
Table 3. Reasons given by clinicians for trusting presumptive diagnosis more than RDT result in Uyo, Akwa Ibom State, Nigeria: 2018 ( $\mathrm{n}=247)$.

\begin{tabular}{lcc}
\hline \multicolumn{1}{c}{ Reasons } & $\mathrm{n}$ & $\%$ \\
\hline RDT's sensitivity is less than $100 \%$ & 9 & $3.6 \%$ \\
RDT's negative result does not rule out malaria & 11 & $4.5 \%$ \\
The specificity of RDT is less than 100\% & 9 & $3.6 \%$ \\
RDT has a high false negative rate & 22 & $8.9 \%$ \\
$\begin{array}{l}\text { RDT has a low sensitivity if the parasite density (load) in the blood sample in low } \\
\text { I have many years of work experience and could therefore rely on my high medical } \\
\text { acumen }\end{array}$ & 8 & $3.2 \%$ \\
$\begin{array}{l}\text { I am a well-trained medical Doctor and can therefore rely on my clinical judgment } \\
\text { I have a rich past experience that I could rely on to make an accurate clinical }\end{array}$ & 8 & $10.5 \%$ \\
$\begin{array}{l}\text { diagnosis } \\
\text { diag }\end{array}$ & 5 & $2.0 \%$ \\
\hline
\end{tabular}

confirmation of malaria as against $45(58.4 \%)$ in the private health facilities. Seventy five (44.1\%) clinicians in the public sector perceived that RDT fits into the dynamic of consultations and did not interfere with patient's flow and clinic activities as against45 (58.4\%) in the private sector. Seventy four (43.5\%) respondents in the public health facilities were of the opinion that RDT often give inaccurate results as against 27 (35.1\%) in the private health facilities. Eighty five (50.0\%) respondents in the public health facilities perceived that RDT is easy to use compared to 41 (53.2\%) of respondents in the private health facilities. Please refer to Table 4 for details.

\subsection{Malaria Diagnosis Practice of Clinicians in Uyo}

Of the total number of respondents trained on RDT use, 34 (68.0\%) in the private health care facilities were compliant with RDT negative result compared to $87(77.0 \%)$ in the public health care facilities. One hundred and sixty two (95.2\%) clinicians in the public sector as against $68(88.2 \%)$ in the private sector reported that RDT was done after consultation. Eight (4.8\%) of clinicians in the public sector and $9(11.7 \%)$ in the private sector reported that RDT was done during consultation. Ninety seven $(57.1 \%)$ of the respondents from the public health facilities and $47(61.0 \%)$ of respondents from the private health facilities reported that they prescribed ACT to suspected malaria cases before parasitological confirmation. The reasons reported by respondents for prescribing ACT with no parasitological confirmation of malaria ranges from non-availability of RDT, $4.0 \%(\mathrm{n}=10)$ to patient overload, $5.3 \%(\mathrm{n}=13)$. Other reasons are presented in Table 5. Fifty six (32.9\%) respondents in public health facilities prescribed ACT to RDT negative clients compared to 27 (35.1\%) in the private sector. The reasons reported for this practice are presented in Table 6. Forty three (25.3\%) clinicians in the public health facilities reported that treatment guidelines were available in the consulting room compared to 21 (27.3\%) respondents in the private health facilities. One hundred and forty nine (87.7\%) clinicians in 
Table 4. Perception of RDT usefulness among clinicians in Uyo, Akwa Ibom State, Nigeria: $2018(\mathrm{n}=247)$.

\begin{tabular}{|c|c|c|c|c|c|}
\hline Response Perception & $\begin{array}{l}\text { Strongly } \\
\text { agree }\end{array}$ & Agree & Undecided & Disagree & $\begin{array}{l}\text { Strongly } \\
\text { disagree }\end{array}$ \\
\hline $\mathrm{RDT}$ is reliable (total) & $87(35.2 \%)$ & $37(15.0 \%)$ & $27(10.9 \%)$ & $66(26.7 \%)$ & $30(12.2 \%)$ \\
\hline Public sector & $54(31.8 \%)$ & $29(17.6 \%)$ & $20(11.8 \%)$ & $43(25.3 \%)$ & $24(14.1 \%)$ \\
\hline Private sector & $33(42.9 \%)$ & $8(10.3 \%)$ & $7(9.1 \%)$ & $23(29.9 \%)$ & $6(7.8 \%)$ \\
\hline $\begin{array}{l}\text { RDT is easy to use } \\
\text { (total) }\end{array}$ & $93(37.7 \%)$ & $33(13.4 \%)$ & $47(19.0 \%)$ & $54(21.9 \%)$ & $20(8.1 \%)$ \\
\hline Public sector & $60(35.3 \%)$ & $25(14.7 \%)$ & $37(21.8 \%)$ & $32(18.2 \%)$ & $16(9.4 \%)$ \\
\hline Private sector & $33(42.9 \%)$ & $8(10.3 \%)$ & $10(13.0 \%)$ & $22(28.6 \%)$ & $4(5.2 \%)$ \\
\hline $\mathrm{RDT}$ is useful (total) & $92(37.3 \%)$ & $40(16.2 \%)$ & $42(17.0 \%)$ & $54(21.9 \%)$ & $19(7.7 \%)$ \\
\hline Public sector & $54(31.8 \%)$ & $33(19.4 \%)$ & $32(18.2 \%)$ & $37(21.8 \%)$ & $14(8.2 \%)$ \\
\hline Private sector & $38(49.4 \%)$ & $7(9.1 \%)$ & $10(13.0 \%)$ & $17(22.1 \%)$ & $5(6.5 \%)$ \\
\hline $\begin{array}{l}\text { I trust clinical judgment } \\
\text { more than RDT (total) }\end{array}$ & $31(12.6 \%)$ & $84(34.0 \%)$ & $19(7.7 \%)$ & $43(17.4 \%$ & $70(28.3 \%)$ \\
\hline Public sector & $24(14.1 \%)$ & $53(31.2 \%)$ & $18(10.6 \%)$ & $35(20.6 \%)$ & $40(23.5 \%)$ \\
\hline Private sector & $7(9.1 \%)$ & $31(40.3 \%)$ & $1(1.3 \%)$ & $8(10.4 \%)$ & $30(39.0 \%)$ \\
\hline $\begin{array}{l}\text { RDT fits into the } \\
\text { dynamics of } \\
\text { consultation (total) }\end{array}$ & $46(18.6 \%)$ & $73(29.6 \%)$ & $46(18.6 \%)$ & $67(27.1 \%)$ & $15(6.1 \%)$ \\
\hline Public sector & $26(15.3 \%)$ & $48(28.2 \%)$ & $36(21.2 \%)$ & $47(27.6 \%)$ & $13(7.4 \%)$ \\
\hline Private sector & $20(26.0 \%)$ & $25(32.5 \%)$ & $10(13.0 \%)$ & $20(26.0 \%)$ & $2(2.6 \%)$ \\
\hline $\begin{array}{c}\text { RDT often gives } \\
\text { inaccurate result (total) }\end{array}$ & $26(19.6 \%)$ & $75(30.5 \%)$ & $31(12.6 \%)$ & $44(17.9 \%)$ & $70(28.3 \%)$ \\
\hline Public sector & $22(12.9 \%)$ & $52(30.6 \%)$ & $22(12.9 \%)$ & $35(20.6 \%)$ & $39(22.9 \%)$ \\
\hline Private sector & $4(5.2 \%)$ & $23(29.9 \%)$ & $9(11.7 \%)$ & $9(11.7 \%)$ & $31(40.3 \%)$ \\
\hline
\end{tabular}

YELLOW $=$ desired response or positive perception. The numerical values of each desired response is 4 or 5 depending on the degree of agreement. GREEN = variable that favors compliance. RED $=$ variable that favors non-compliance.

the public and $57(74.0 \%)$ in the private health facilities self-reported that they complied with RDT positive results. One hundred and forty (82.4\%) clinicians in the public health facilities reported that their facilities experienced stock out of RDT kit at some point since their introduction compared to 59 (76.6\%) in the private health facilities. Please refer to Table 7 for details.

\subsection{Compliance with RDT Results}

Concordance between compliance as derived from clinic registers, patient folders and laboratory registers on one hand, and clinicians' self-reported compliance on the other hand, was high (sensitivity $97.6 \%$; specificity $98.8 \%$; overall percent agreement $98.1 \%$, percent positive agreement $96.7 \%$ ). Consistent compliance with positive and negative RDT results in the two weeks prior to the survey could not be established from hospital records for 5 (2.9\%) clinicians in the public sector and $2(2.6 \%)$ in the private sector respectively (in these cases, 
Table 5. The reasons reported by clinicians for prescribing ACT before parasitological confirmation in Uyo, Akwa Ibom State, Nigeria: $2018(\mathrm{n}=247)$

\begin{tabular}{llc}
\hline \multicolumn{1}{c}{ Reasons } & $\mathbf{n}$ & $\%$ \\
\hline Malaria RDT has a high falls positive rate & 9 & $3.6 \%$ \\
Malaria is endemic in Nigeria & 8 & $3.2 \%$ \\
Delay in release of test result from the laboratory & 5 & $2.0 \%$ \\
Need to commence treatment before patient deteriorate or progress to severe & 10 & $4.0 \%$ \\
malaria & 22 & $8.9 \%$ \\
Neonates are treated without RDT result & 11 & $4.5 \%$ \\
Patient's pressure and demand for prescription without RDT result & 10 & $4.0 \%$ \\
Stock-out of RDT kit & 26 & $10.5 \%$ \\
I trust my clinical judgment and past experience & 11 & $4.5 \%$ \\
If symptom and signs are very clear & 9 & $3.6 \%$ \\
RDT is done in the laboratory (not point-of-care) and results are not released on & & \\
time & 13 & $5.3 \%$ \\
Clinical diagnosis saves time and money & 9 & $3.6 \%$ \\
If the cardinal symptoms and signs of malaria is present & 8 & $3.2 \%$ \\
If patient is severely ill, chemotherapy is started before RDT result is out & 9 & $3.6 \%$ \\
If the patient has no money for RDT & 11 & $4.5 \%$ \\
To prevent disease progression & 26 & $10.5 \%$ \\
If patient so demand & 13 & $5.2 \%$ \\
For prophylaxis & 22 & $8.9 \%$ \\
RDT is almost always negative & 1 & $0.4 \%$ \\
If patients presents at odd times (e.g. late at night) when the laboratory has closed & 7 & $2.8 \%$ \\
In under fives to prevent disease progression & 8 & $3.2 \%$ \\
I am yet to be trained on RDT & 9 & $3.6 \%$ \\
RDT is difficult to use & & \\
\hline & &
\end{tabular}

Table 6. The reasons reported by clinicians for prescribing ACT to RDT negative patients in Uyo, Akwa Ibom State, Nigeria: $2018(\mathrm{n}=247)$.

\begin{tabular}{lcc}
\hline \multicolumn{1}{c}{ Reasons } & n & $\%$ \\
\hline $\begin{array}{l}\text { During the rainy season when transmission is high, I prescribe ACT to RDT } \\
\text { negative clients }\end{array}$ & 9 & $3.6 \%$ \\
Malaria RDT's specificity is less than 100\% & 9 & $3.6 \%$ \\
Malaria RDT has a high false negative rate & 22 & $8.9 \%$ \\
Malaria is endemic in Nigeria & 11 & $4.5 \%$ \\
In order not to miss any malaria case, all febrile patients should be treated with & 8 & $3.2 \%$ \\
malaria & 1 & $0.4 \%$ \\
Human and instrumental factors can bring about a false negative result & 63 & $25.5 \%$ \\
I distrust RDT negative result & 11 & $4.5 \%$ \\
\hline
\end{tabular}


Table 7. Malaria diagnosis practice of clinicians in Uyo, Nigeria: $2018(\mathrm{n}=247)$.

\begin{tabular}{|c|c|c|}
\hline Variable & $\mathbf{n}$ & $\%$ \\
\hline Clinicians who adhere to national treatment guidelines $\dagger$ & 122 & 49.4 \\
\hline Clinicians who adhere to national treatment guidelines (public sector) $\dagger$ & 82 & 48.2 \\
\hline Clinicians who adhere to national treatment guidelines (private sector) $\dagger$ & 40 & 51.9 \\
\hline Clinicians who rely on presumptive diagnosis ${ }^{\star}$ & 103 & 41.7 \\
\hline Clinicians who rely on presumptive diagnosis (public sector) ${ }^{\star}$ & 73 & 42.9 \\
\hline Clinicians who rely on presumptive diagnosis (private sector) ${ }^{\star}$ & 30 & 39.0 \\
\hline Clinicians who experience stock-out at some point (overall) ${ }^{\star \star}$ & 199 & 80.6 \\
\hline Clinicians who experience stock-out at some point (public sector) ${ }^{\star \star}$ & 140 & 82.4 \\
\hline Clinicians who experience stock-out at some point (private sector) ${ }^{* *}$ & 59 & 76.6 \\
\hline Clinicians who reported readily available SOPs in consulting room (overall) & 64 & 25.9 \\
\hline Clinicians who reported readily available SOPs in consulting room (public sector) & 43 & 25.3 \\
\hline Clinicians who reported readily available SOPs in consulting room (private sector) & 21 & 27.3 \\
\hline Clinicians who reported RDT is done during consultation (overall) & 17 & 6.9 \\
\hline Clinicians who reported $\mathrm{RDT}$ is done during consultation (public sector) & 8 & 4.8 \\
\hline Clinicians who reported RDT is done during consultation (private sector) & 9 & 11.7 \\
\hline Clinicians who reported RDT is done after consultation (overall) & 230 & 93.1 \\
\hline Clinicians who reported RDT is done after consultation (public sector) & 162 & 95.2 \\
\hline Clinicians who reported RDT is done after consultation (private sector) & 68 & 88.3 \\
\hline
\end{tabular}

$\dagger$ Apart from complying with positive and negative RDT results, clinician did not prescribe ACT before parasitological confirmation of malaria in the 2 weeks prior to survey ( 2 weeks adopted from Pulfford et al. 2014). ${ }^{*}$ Clinician prescribes ACT to client before parasitological confirmation. ${ }^{* *}$ Clinician experience RDT stock-out at some point in time in the 4 weeks prior to survey (4 weeks adopted from Mbacham et al. 2014).

testing was established as self-reported by clinician, and were regarded as invalid responses and treated as missing data). Missing data were excluded from percentage calculations. Details on compliance are in Table 8.

\subsection{Factors Associated with Compliance with RDT Results}

Inclusion of all factors from the bivariate analysis with a p-value $<0.25$ in a step-wise logistic regression revealed that knowledge about RDT use contributed significantly to compliance with RDT negative result. It was also demonstrated that perception of RDT usefulness, knowledge of RDT use and facility type contributed significantly to compliance with RDT positive result. The other factors considered in this study were not significant contributors after controlling for confounding. Please refer to Tables 9-12 for details.

\section{Discussion, Conclusion and Recommendations}

\subsection{Discussion}

Compliance with RDT result is a topical issue given the increasing international concern of antimicrobial resistance. Almost two-third of the clinicians in Uyo 
Table 8. Compliance with RDT results among clinicians in Uyo, Nigeria: $2018(\mathrm{n}=247)$.

\begin{tabular}{lcc}
\hline \multicolumn{1}{c}{ Variable } & n & $\%$ \\
\hline Compliance with RDT results $\dagger$ & 151 & 61.1 \\
Compliance with RDT results in the public sector $\dagger$ & 105 & 61.8 \\
Compliance with RDT results in the private sector $\dagger$ & 46 & 59.7 \\
Compliance with RDT negative result ${ }^{* *}$ & 164 & 66.4 \\
Compliance with RDT negative result in the public sector ${ }^{* *}$ & 114 & 67.1 \\
Compliance with RDT negative result in the private sector & $* * *$ \\
Compliance with RDT positive result $\dagger \dagger$ & 50 & 64.9 \\
Compliance with RDT positive result in the public sector $\dagger \dagger$ & 206 & 83.4 \\
Compliance with RDT positive result in the private sector $\dagger \dagger$ & 149 & 87.7 \\
Clinicians who prescribe ACT before parasitological confirmation (overall) & 57 & 74.0 \\
Clinicians who prescribe ACT before parasitological confirmation (public sector) & 73 & 42.9 \\
Clinicians who prescribe ACT before parasitological confirmation (private sector) & 30 & 39.0 \\
\hline
\end{tabular}

$\dagger \dagger$ Clinician prescribe ACT to client with RDT positive result in the 2 weeks prior to survey (2 weeks adopted from Pulford et al. 2014). ${ }^{* *}$ Clinician did not prescribe ACT to client with RDT negative result in the 2 weeks prior to survey. $†$ Clinician comply with both positive and negative RDT results consistently in the 2 weeks prior to the survey.

complied with malaria RDT result. Compliance rate was higher with RDT positive result compared to RDT negative result. Compliance was generally higher in the public sector. After controlling for confounding, compliance with RDT negative result was driven by knowledge of RDT use. There was no association between facility type and compliance with RDT negative result. Compliance with $\mathrm{RDT}$ positive result on the other hand was driven by clinician's perceptions of malaria RDT usefulness in the diagnostic process; knowledge of RDT use and facility type. There was no association between socio-demographic factors and compliance with RDT result. Less than half of the respondents had good knowledge of RDT use. The proportion of respondents with good knowledge was also higher in the private sector. Less than half of the respondents had positive perception of malaria RDT usefulness. The proportion of respondents with positive perception was also higher in the private sector. A little below half of the respondents rely on presumptive diagnosis: The proportion of respondents who relied on presumptive diagnosis was higher in the public sector.

This study revealed that 147 (87.7\%) clinicians in the public sector compared to $57(74.0 \%)$ in the private sector comply with RDT positive result. The proportion of clinicians, who were compliant with malaria RDT negative results, was $67.1 \%$ in the public sector and $64.9 \%$ in the private sector. Compliance with RDT negative result for private sector is consistent with that of Mokuolu and associates who reported a rate of $69.6 \%$ in the private sector [13]. However, it varied considerably from an earlier study conducted in Zambia which revealed a compliance rate of $100.0 \%$ and $99.4 \%$ in the public sector of the two districts of 
Table 9. Factors associated with compliance with malaria RDT negative results among clinicians in Uyo, Akwa Ibom State: $2018(\mathrm{n}=247)$.

\begin{tabular}{|c|c|c|c|c|}
\hline Variable & $\begin{array}{c}\text { Non-compliant } \\
\#(\%)\end{array}$ & $\begin{array}{c}\text { Compliant } \\
\#(\%)\end{array}$ & OR $(95 \% \mathrm{CI})$ & $p$ value \\
\hline \multicolumn{5}{|c|}{ Knowledge about } \\
\hline Poor & $81(57.9 \%)$ & $59(42.1 \%)$ & & \\
\hline Good & $2(1.9 \%)$ & $105(98.1 \%)$ & $72.1(17.90-617.20)^{*}$ & $<0.0001$ \\
\hline \multicolumn{5}{|c|}{$\begin{array}{c}\text { Perception about RDT } \\
\text { usefulness }\end{array}$} \\
\hline Negative & $79(58.5 \%)$ & $56(41.5 \%)$ & & \\
\hline Positive & $4(3.6 \%)$ & $108(96.4 \%)$ & $38.1(13.26-148.9)^{*}$ & $<0.0001$ \\
\hline \multicolumn{5}{|c|}{ Received RDT training } \\
\hline No & $40(52.3 \%)$ & $36(47.4 \%)$ & & \\
\hline yes & $43(25.2 \%)$ & $128(51.274 .9 \%)$ & $3.31(1.88-5.83)^{*}$ & $<0.0001$ \\
\hline \multicolumn{5}{|c|}{$\begin{array}{c}\text { Received RDT } \\
\text { supportive supervision }\end{array}$} \\
\hline No & $57(36.3 \%)$ & $100(63.7 \%)$ & & \\
\hline Yes & $26(28.9 \%)$ & $64(71.1 \%)$ & $1.40(0.80,2.46)$ & 0.29 \\
\hline \multicolumn{5}{|c|}{$\begin{array}{c}\text { National } \\
\text { guidelines- } \\
\text { readily available }\end{array}$} \\
\hline No & $69(37.7 \%)$ & $114(62.3 \%)$ & & \\
\hline Yes & $14(21.9 \%)$ & $50(78.1 \%)$ & $2.2(1.11,4.20)^{*}$ & 0.03 \\
\hline \multicolumn{5}{|c|}{$\begin{array}{l}\text { Diagnostic capacity for } \\
\text { other common causes of } \\
\text { fever }\end{array}$} \\
\hline No & $1(20.0 \%)$ & $4(80.00 \%)$ & & \\
\hline Yes & $82(33.9 \%)$ & $160(66.1 \%)$ & $0,49(0.01,5.05)$ & 0.67 \\
\hline \multicolumn{5}{|c|}{$\begin{array}{c}\text { Number of out-patients } \\
\text { seen in a day } \\
\text { (patient overload ) }\end{array}$} \\
\hline$\leq 25$ & $68(33.0 \%)$ & $138(72.0 \%)$ & & \\
\hline$>25$ & $15(36.6 \%)$ & $26(63.4 \%)$ & $1.18(0.58-2.35)$ & 0.79 \\
\hline \multicolumn{5}{|c|}{ Stock-out of RDT kit } \\
\hline No & $17(35.4 \%)$ & $31(64.6 \%)$ & & \\
\hline Yes & $66(33.2 \%)$ & $133(66.8 \%)$ & $1.1(0.57,2.14)$ & 0.90 \\
\hline \multicolumn{5}{|l|}{$\begin{array}{l}\text { Level of medical } \\
\text { education }\end{array}$} \\
\hline Graduate & $67(32.2 \%)$ & $141(67.8 \%)$ & & \\
\hline Post-graduate & $16(41.0 \%)$ & $23(59.0 \%)$ & $0.68(0.34,1.38)$ & 0.38 \\
\hline \multicolumn{5}{|l|}{ Facility type } \\
\hline Private sector & $27(26.3 \%)$ & $50(73.7 \%)$ & & \\
\hline Public sector & $56(12.3 \%)$ & $114(87.7 \%)$ & $1.1(0.62,1.94)$ & 0.86 \\
\hline
\end{tabular}




\section{Continued}

\begin{tabular}{|c|c|c|c|c|}
\hline \multicolumn{5}{|c|}{$\begin{array}{l}\text { Work experience } \\
\text { in years }\end{array}$} \\
\hline$<6$ years & $32(35.2 \%)$ & $59(64.8 \%)$ & & \\
\hline$\geq 6$ years & $51(32.7 \%)$ & $105(67.3 \%)$ & $1.12(0.65,1.93)$ & 0.80 \\
\hline \multicolumn{5}{|c|}{$\begin{array}{c}\text { When last RDT training } \\
\text { was received }\end{array}$} \\
\hline$<1$ year & $15(27.8 \%)$ & $39(72.2 \%)$ & & \\
\hline$\geq 1$ year & $28(23.9 \%)$ & $89(76.1 \%)$ & $1.22(0176-2.54)$ & 0.73 \\
\hline \multicolumn{5}{|c|}{$\begin{array}{c}\text { When last supportive } \\
\text { supervision was } \\
\text { received }\end{array}$} \\
\hline$<1$ year & $12(25.0 \%)$ & $36(55.5 \%)$ & & \\
\hline$\geq 1$ year & $13(31.7 \%)$ & $28(68.3 \%)$ & $0.72(0.28,1.81)$ & 0.64 \\
\hline \multicolumn{5}{|c|}{ Marital status } \\
\hline Married & $72(33.3 \%)$ & $144(75.0 \%)$ & & \\
\hline Single & $11(35.5 \%)$ & $20(64.5 \%)$ & $0.9(0.41-2.00)$ & 0.97 \\
\hline \multicolumn{5}{|l|}{ Sex } \\
\hline Female & $29(37.7 \%)$ & $48(62.3 \%)$ & & \\
\hline Male & $54(31.7 \%)$ & $116(68.2 \%)$ & $1.3(0.74-2.28)$ & 0.45 \\
\hline
\end{tabular}

Chongwe and Kalomo respectively [19]. This very high compliance rate was because the Zambia study was a prospective evaluation in which the participants were trained prior to the study. Mubi and associates on the other hand reported a compliance rate of $33.0 \%$ to RDT negative result in PHCs (Primary Health Centers) in the public sector [14]. Anecdotal evidence suggests that the relatively low compliance rate in the private sector was because clinicians in the private sector are more business-oriented. Clinicians in the public sector on the other hand have a role that is more of humanitarian service than a business [20]. The implication of this finding is that more has to be done to improve on the rate of compliance with negative RDT results especially in the private.

After controlling for confounding, this study demonstrated that knowledge of RDT use was significantly associated with compliance with RDT negative result. It also demonstrated that the following factors were significantly associated with compliance with RDT positive result: Perception of RDT usefulness; knowledge of RDT use; and facility type (whether public or private health facility). Chanda et al., in a related study conducted in Zambia implicated training, supervision, quality assurance and continuous availability of test kits as determinants of compliance with RDT results [21]. In another related study conducted in sub-Saharan Africa, the following factors were reported as predictors of compliance with RDT negative results: patient expectations, work experience, skepticism of result, health workers cadres and perception [16]. Another related study conducted in Nigeria reported that access to treatment guidelines; availability 
Table 10. Factors associated with compliance with malaria RDT positive results among clinicians in Uyo, Akwa Ibom State: 2018 ( $\mathrm{n}=247)$.

\begin{tabular}{|c|c|c|c|c|}
\hline Variable & $\begin{array}{c}\text { Non-compliant } \\
\#(\%)\end{array}$ & $\begin{array}{c}\text { Compliant } \\
\#(\%)\end{array}$ & OR $(95 \% \mathrm{CI})$ & $p$ value \\
\hline \multicolumn{5}{|l|}{ Knowledge about } \\
\hline \multicolumn{5}{|c|}{ RDT use } \\
\hline Poor & $36(25.7 \%)$ & $104(74.3 \%)$ & & \\
\hline Good & $5(4.7)$ & $102(95.3 \%)$ & $7.1(2.70 .18 .72)$ & $<0.001^{*}$ \\
\hline \multicolumn{5}{|c|}{$\begin{array}{c}\text { Perception about RDT } \\
\text { usefulness }\end{array}$} \\
\hline Negative & $37(27.4 \%)$ & $98(72.6 \%)$ & & \\
\hline Positive & $4(3.6 \%)$ & $108(96.4 \%)$ & $10.2(3.56,40.54)$ & $<0.001^{*}$ \\
\hline \multicolumn{5}{|c|}{ Received RDT training } \\
\hline No & $13(17.1 \%)$ & $63(82.9 \%)$ & $1.05(0.51-2.16)$ & \\
\hline Yes & $28(16.4 \%)$ & $143(83.6 \%)$ & & 0.99 \\
\hline \multicolumn{5}{|c|}{$\begin{array}{c}\text { Received RDT } \\
\text { supportive supervision }\end{array}$} \\
\hline No & $29(18.5 \%)$ & $128(81.5 \%)$ & & \\
\hline Yes & $12(13.3 \%)$ & $78(86.7 \%)$ & $1.47(0.71,3.05)$ & 0.39 \\
\hline \multicolumn{5}{|c|}{$\begin{array}{c}\text { National } \\
\text { guidelines-readily } \\
\text { available }\end{array}$} \\
\hline No & $32(17.9 \%)$ & $151(82.1 \%)$ & & \\
\hline Yes & $9(14.1 \%)$ & $55(85.9 \%)$ & $1.30(0.58,2.89)$ & 0.66 \\
\hline \multicolumn{5}{|c|}{$\begin{array}{l}\text { Diagnostic capacity } \\
\text { for other common } \\
\text { causes of fever }\end{array}$} \\
\hline No & $2(40.0 \%)$ & $3(60.00 \%)$ & & \\
\hline Yes & $39(16.1 \%)$ & $203(83.9 \%)$ & $3.47(0.28,31.11)$ & 0.19 \\
\hline \multicolumn{5}{|c|}{$\begin{array}{c}\text { Number of out-patients } \\
\text { seen in a day } \\
\text { (patient overload?) }\end{array}$} \\
\hline$\geq 25$ & $11(18.0 \%)$ & $50(82.0 \%)$ & & \\
\hline$<25$ & $30(16.1 \%)$ & $156(83.9 \%)$ & $1.14(0.53,2.45)$ & 0.88 \\
\hline \multicolumn{5}{|c|}{ Stock-out of RDT kit } \\
\hline No & $36(17.5 \%)$ & $170(82.5 \%)$ & & \\
\hline Yes & $12(29.3 \%)$ & $29(70.7 \%)$ & $1.96(0.91,4.35)$ & 0.13 \\
\hline \multicolumn{5}{|l|}{$\begin{array}{l}\text { Level of medical } \\
\text { education }\end{array}$} \\
\hline Graduate & $32(15.4 \%)$ & $176(84.6 \%)$ & $1.67(0.71,3.85)$ & \\
\hline Post-graduate & $9(23.1 \%)$ & $30(76.9 \%)$ & & 0.34 \\
\hline \multicolumn{5}{|l|}{ Facility type } \\
\hline Private sector & $20(26.3 \%)$ & $56(73.7 \%)$ & & \\
\hline Public sector & $21(12.3 \%)$ & $150(87.7 \%)$ & $2.55(1.29,5.06)$ & $0.01^{*}$ \\
\hline
\end{tabular}




\section{Continued}

\begin{tabular}{ccccc}
\hline $\begin{array}{c}\text { Work experience } \\
\text { in years } \\
<6 \text { years }\end{array}$ & $23(16.4 \%)$ & $117(83.6 \%)$ & $1.03(0.52,2.04)$ & \\
$\quad \geq 6$ years & $18(16.8 \%)$ & $89(83.2 \%)$ & & 0.99 \\
$\begin{array}{c}\text { When last RDT training } \\
\text { was received }\end{array}$ & & & & \\
$\quad>1$ year & $8(14.8 \%)$ & $46(86.2 \%)$ & $0.84(0.34-2.06)$ & 0.0 .89 \\
$\quad \leq 1$ year & $20(17.1 \%)$ & $97(82.9 \%)$ & & \\
$\begin{array}{c}\text { When last supportive } \\
\text { supervision was } \\
\text { received }\end{array}$ & & & & \\
$\geq 1$ year & $35(45.5 \%)$ & $42(55.5 \%)$ & $1.20(0.35,4.00)$ & \\
$<1$ year & $6(50.0 \%)$ & $6(50.0 \%)$ & & 0.99 \\
\hline
\end{tabular}

Table 11. Predictors of clinicians' compliance with RDT negative results, Uyo: 2018.

\begin{tabular}{cccc}
\hline Variable & Adjusted OR & 95\% CI & $p$ value \\
\hline Perception about RDT usefulness & 2.7 & $0.50-114.29$ & $p=0.25$ \\
Knowledge about RDT use & 24.95 & $2.92-213.52$ & $p=0.003^{*}$ \\
Received RDT Training & 1.28 & $0.64-2.50$ & $p=0.48$ \\
Treatment guidelines-readily available & 1.39 & $0.61-3.23$ & $p=0.44$ \\
\hline
\end{tabular}

Table 12. Predictors of clinicians' compliance with RDT positive results, Uyo: 2018.

\begin{tabular}{cccc}
\hline Variable & Adjusted OR & $95 \%$ CI & $p$ value \\
\hline $\begin{array}{c}\text { Perception about RDT } \\
\text { usefulness }\end{array}$ & 10.2 & $3.50-29.63$ & $p<0.001^{*}$ \\
Knowledge about RDT use & 10.0 & $\mathbf{2 . 7 0 - 2 0 . 0 0}$ & $p=0.001^{*}$ \\
$\begin{array}{c}\text { Stock-out of RDT kit } \\
\text { Availability of diagnostic } \\
\text { capacity for other common } \\
\text { febrile illness }\end{array}$ & 12.5 & $0.83-10.00$ & $p=0.1$ \\
Facility type-public sector & 7.0 & $0.8-61.0$ & $p=0.08$ \\
\hline
\end{tabular}

${ }^{*}$ Statistically significant association.

of test kit and training on malaria case management were not associated with compliance with RDT result [22]. This study's analysis suggests that RDT stock-out was not significantly associated with compliance with test result. This finding is consistent with Burchett and associates who suggested that supplies are essential but insufficient to influence compliance with test result [20]. A clinician with a positive perception about the usefulness of malaria RDT in the diagnostic process would refer patients than rely on presumptive diagnosis in the event of RDT stock-out. In a related study conducted in Cameroon, Mbacham et al. demonstrated that enhanced training is significantly associated with compliance with RDT negative result. They also demonstrated that enhanced training has no 
effect on compliance with RDT positive result and adherence to treatment guidelines [23]. Cundill et al. in another study conducted in Tanzania also demonstrated that training may influence compliance with RDT negative result, but has no effect on compliance with RDT positive result [24]. Some other related study conducted in Burkina Faso revealed that even enhanced training has no effect on compliance with RDT negative results [25] but rather the availability and access to alternative diagnostic methods for other common febrile illnesses [14]. The implication of these findings is that the content of most training in malaria RDT is just basic, not taking into consideration contextual challenges. This suggests the need for NMEP to develop an enhanced training programme that will take into consideration the different contexts and settings.

In this study $61.0 \%$ of clinicians in the public sector had good knowledge about RDT use compared to $48.0 \%$ in the private sector. In a related study conducted in south east Nigeria, Uzochukwu and associates reported that $72.2 \%$ of public and $50.0 \%$ of private health workers had good knowledge about malaria RDT use [11]. Some other study conducted in Nigeria revealed that over $70.0 \%$ of health workers in the private sector had good knowledge about malaria RDT use [13]. A related study conducted in Uganda reported that $80 \%$ of clinicians had good knowledge about RDT use in the public sector [26]. The relatively high rate reported by Kyabayinze et al. was attributed to the fact that these clinicians received training on the use of $\mathrm{RDT}$ a week prior to the survey. The variance observed in the findings from the different study settings may also be attributed to the difference in the cut-off point for good knowledge adopted for the different studies. The public health implication of these findings is that more need to be done in the area of improving on the knowledge of health providers in RDT use especially in the private sector.

This study revealed that $85(50.0 \%)$ clinicians in the public sector and 41 (53.2\%) in the private sector perceived that RDT is easy to use. In another cross sectional study conducted in Tanzania $70.0 \%$ of health workers in the public sector reported that RDT was easy to use [14]. This is likely to contribute to less clinicians relying on presumptive diagnosis. It underscores the need for NMEP to develop RDT training programme that will address specific challenges when using RDT kit. This study also revealed that 77 (45.3\%) clinicians in the public health facilities are of the opinion that RDT often give inaccurate (false negative) results as against $51(66.2 \%)$ in the private health facilities. In another cross sectional study conducted in Tanzania 70.0\% of health workers in the public sector reported that RDT often give inaccurate test results [14]. As malaria transmission declines globally, the problem of accurate diagnosis becomes more important because of the increasing need to detect low-density infection in the bid to wipe out parasite reservoirs even in the asymptomatic. This underscores the need for all stakeholders to understand the limitations of RDTs so that they can adjust diagnostic strategies and put test results in the right perspectives. Stakeholders should be well informed about the WHO's recommended RDTs. The WHO recommends malaria RDTs with a limit of detection (LOD) of 200 para- 
sites per uL. Rapid diagnostic test kits with an LOD above 200 parasites/uL may not be able to detect low density parasitaemia typical of low transmission settings. The shift from pre-elimination to elimination phase requires the use of more sensitive RDT kits that will be able to detect low density parasitemia as may be found in asymptomatic infection [27]. Modifying the current RDT process by adding another step (sample extraction) increases RDTs sensitivity and reduces the incidence of false negative results. Sample extraction brings the LOD of RDTS to levels as low as 3 - 33 parasites per uL so that low density parasitaemia can be detected [28].

A total of 103 (41.7\%) respondents relied on presumptive diagnosis. A cluster randomized study conducted in Cameroon revealed a rate of $29.2 \%$ and $43.9 \%$ after clinicians' exposure to basic and enhanced training on case management respectively [23]. An observational study conducted in Tanzania reported 4.1\% clinicians relied on presumptive diagnosis [29]. Another observational study conducted in Mozambique reported 6.6\% clinicians relied on presumptive diagnosis [30]. In the case of Bottaeu et al, missing data were excluded from the computation. Some other observational study carried out in Zambia revealed a presumptive diagnosis rate of $60.3 \%$ for clinicians [12]. A cross sectional study conducted in Malawi reported 13.1\% clinicians relied on presumptive diagnosis [31]. Another cross sectional study conducted in Nigeria reported a rate of $40.0 \%$ for clinicians relying on presumptive diagnosis [11]. Their finding was consistent with our study. A more recent cross sectional study conducted in Tanzania revealed a rate of $9.5 \%$ for clinicians who rely on presumptive diagnosis [14]. Another recent cross sectional study carried out in Zanzibar reported $0.1 \%$ clinicians relying on presumptive diagnosis [32]. The current study also reported that more clinicians in the public sector relied on presumptive diagnosis. This finding is not consistent with that of Bamiselu et al. 2016 who revealed that presumptive diagnosis of malaria was higher among private (94.9\%) health care providers compared to health providers in the public (22.7\%) sector. The variance is attributed to the previous exposures of the study participants to basic or enhanced training. Those exposed to enhanced training exhibited higher rate of presumptive diagnosis.

\subsection{Limitation of the Study}

The questionnaires were self-administered; therefore the accuracy of the information obtained from them depends entirely on the respondent providing truthful response. The responses of the participants may have been affected by one or more of the following biases: questionnaire error, respondent error, abstracting error and coding error. This may have distorted the true picture of compliance to malaria RDT result. This limitation was addressed by assuring participants of the strict confidentiality of the information they provide. Further measures taken included: providing both direct and indirect questions in the questionnaire to determine compliance status of participant; removing identifiers from the questionnaires to ensure privacy of participants and validating par- 
ticipants' responses with hospital records.

In determining compliance, perception and the level of knowledge of respondents, some assumptions were made. These assumptions may have adversely affected the result of the study to an extent, because these assumptions were made about things we were uncertain about. For example, the assumption that scoring $75.0 \%$ in the objective questions testing for knowledge signifies good knowledge. Others include the assumption made by converting the responses to questions testing for perception into binary responses to enable bivariate analysis. Moreover, the assumption that the response of participants to questions testing for compliance is the truth.

\subsection{Conclusion}

Most clinicians were compliant with RDT result. Compliance rate was higher with RDT positive results compared to RDT negative result. Compliance was generally higher in the public sector. After controlling for confounding, compliance with RDT negative result was driven by knowledge of RDT use. There was no association between facility type and compliance with RDT negative result. Compliance with RDT positive result was driven by clinician's perceptions of malaria RDT usefulness in the diagnostic process; knowledge of RDT use and facility type. There was no association between socio-demographic factors and compliance with RDT result. Less than half of the respondents had good knowledge of RDT use. The proportion of respondents with good knowledge was also higher in the private sector. Less than half of the respondents had positive perception of malaria RDT usefulness. The proportion of respondents with positive perception was also higher in the private sector. A little below half of the respondents rely on presumptive diagnosis: The proportion of respondents who relied on presumptive diagnosis was higher in the public sector.

\subsection{Public Health Action}

Feedback was given to each participant at the end of the study; they were contacted through the phone numbers collected when the self-administered questionnaires were issued to them. Findings of the study were made available to the Akwa Ibom State Ministry of Health, the Nigeria Field Epidemiology and Laboratory Training Programme.

\subsection{Recommendations}

1) National Malaria Elimination Programme (NMEP) should ensure that efforts to improve compliance with RDT results are focused on clinicians with poor knowledge of RDT use, negative perception of RDT usefulness and those in the private sector.

2) There should be regular supportive supervision by evaluators from the Ministry of Health, providing constant reminder to health providers, of the advantages of malaria RDT over presumptive diagnosis, may also improve out- 
come.

3) Mass communication campaigns and community sensitization activities, emphasizing the need for patients to always insist on parasitological confirmation before chemotherapy. Patients should be made to appreciate the demerits of pressurizing their physician and demanding for prescription before parasitological confirmation of malaria.

4) Supplies of RDT kits to facilities should be stabilized to prevent stock-out and its sequel.

5) Providers should be exposed to enhanced mRDT training after completion of their basic mRDT training. During this enhanced training, contextual factors that may influence their perceptions about mRDT use should be addressed in detail.

6) In the absence of diagnostics for differentials of fever, clinicians should be encouraged to build their trust in mRDT results by referring and following up mRDT negative patients to see if they recovered without anti-malarial. They could also test by microscopy as well as mRDT to build trust.

7) Providers should have regular supportive supervision and feedback by text message to improve compliance. Detailed guidance on how to manage mRDT negative results and tests to prescribe in order to implicate common non-malarial febrile illness should be provided in the national malaria treatment guideline.

8) However, further research involving explicit (analytic) study of compliance with RDT results in Uyo is recommended.

\section{Consent for Publication}

Not applicable.

\section{Availability of Data and Materials}

The datasets supporting the conclusions of this article are included within the article.

\section{Funding}

No financial support was received for this study.

\section{Author's Contributions}

GBE conceived the study, participated in its design, acquisition of data, analysis and interpretation of data and wrote the draft manuscript. BE, GB, ASA, DD and IOAmade substantial contributions to conception and study design, data analysis and interpretation, and participated in the critical revision of the manuscript for important intellectual content.

\section{Acknowledgements}

We are grateful to all clinicians who participated in the study. We are also grateful to the research assistants who worked tirelessly to ensure the study was a success. We would like to acknowledge the AkwaIbom State Ministry of Health 
and Research Ethics Review committee for their support. Above all we are grateful to the Almighty God of Mercies and the Lord Jesus Christ of Nazareth for everything.

\section{Conflicts of Interest}

The authors declare that they have no competing interests.

\section{References}

[1] WHO (2015) World Malaria Report 2015.

[2] World Health Organization (2010) World Malaria Report. World Health [Internet]. WHO/HTM/GM(December), 238. http://www.who.int/malaria/world_malaria_report_2011/9789241564403_eng.pdf

[3] Boyce, M.R. and O’Meara, W.P. (2017) Use of Malaria RDTs in Various Health Contexts across Sub-Saharan Africa: A Systematic Review. BMC Public Health, 17, 470. https://doi.org/10.1186/s12889-017-4398-1

[4] Shillcutt, S., Morel, C., Goodman, C., Coleman, P., Bell, D., Whitty, C.J.M., et al. (2008) Cost-Effectiveness of Malaria Diagnostic Methods in Sub-Saharan Africa in an Era of Combination Therapy. Bulletin of the World Health Organization, 86, 101-110. https://doi.org/10.2471/BLT.07.042259

[5] Selimuzzaman, S.M., Islam, S.J., Nahar, Z., Das, R., Rahman, M.A. and Rahman, M.A. (2010) Malarigen Malaria Pf/Pv Antigen Rapid Test: A Simple and Effective Tool for Diagnosis of Malaria in the Far-Flung Hilly Areas of Bangladesh. Mymensingh Medical Journal, 19, 94-99.

[6] Pulford, J., Smith, I., Mueller, I., Siba, P.M. and Hetzel, M.W. (2016) Health Worker Compliance with a "Test and Treat" Malaria Case Management Protocol in Papua New Guinea. PLOS ONE, 11, e0158780. https://doi.org/10.1371/journal.pone.0158780

[7] Pulford, J., Siba, P.M., Mueller, I. and Hetzel, M.W. (2014) The Exit Interview as a Proxy Measure of Malaria Case Management Practice: Sensitivity and Specificity Relative to Direct Observation. BMC Health Services Research, 14, 628. https://doi.org/10.1186/s12913-014-0628-8

[8] D’Acremont, V., Lengeler, C. and Genton, B. (2010) Reduction in the Proportion of Fevers Associated with Plasmodium falciparum Parasitaemia in Africa: A Systematic Review. Malaria Journal, 9, 240.

http://www.pubmedcentral.nih.gov/articlerender.fcgi?artid=2936918\&tool=pmcent rez\&rendertype $=$ abstract https://doi.org/10.1186/1475-2875-9-240

[9] Bisoffi, Z., Tinto, H., Sirima, B.S., Gobbi, F., Angheben, A., Buonfrate, D., et al. (2013) Should Malaria Treatment Be Guided by a Point of Care Rapid Test? A Threshold Approach to Malaria Management in Rural Burkina Faso. PLoS ONE, 8 , e58019. https://doi.org/10.1371/journal.pone.0058019

[10] Modrek, S., Schatzkin, E., De La Cruz, A., Isiguzo, C., Nwokolo, E., Anyanti, J., et al. (2014) SMS Messages Increase Adherence to Rapid Diagnostic Test Results among Malaria Patients: Results from a Pilot Study in Nigeria. Malaria Journal, 13, 69. https://www.scopus.com/inward/record.uri?eid=2-s2.0-84895930830\&doi=10.1186 \%2F1475-2875-13-69\&partnerID=40\&md5=fcebf125dbdebaad3800811366386071

[11] Uzochukwu, B.S.C., Onwujekwe, E., Ezuma, N.N., Ezeoke, O.P., Ajuba, M.O. and Sibeudu, F.T. (2011) Improving Rational Treatment of Malaria: Perceptions and In- 
fluence of RDTs on Prescribing Behaviour of Health Workers in Southeast Nigeria. PLOS ONE, 6, e14627. https://doi.org/10.1371/journal.pone.0014627

[12] Manyando, C., Njunju, E.M., Chileshe, J., Siziya, S. and Shiff, C. (2014) Rapid Diagnostic Tests for Malaria and Health Workers' Adherence to Test Results at Health Facilities in Zambia. Malaria Journal, 13, 166.

http://www.ncbi.nlm.nih.gov/pubmed/24885996

https://doi.org/10.1186/1475-2875-13-166

[13] Mokuolu, O.A., Ntadom, G.N., Ajumobi, O.O., Alero, R.A., Wammanda, R.D., Adedoyin, O.T., et al. (2016) Status of the Use and Compliance with Malaria Rapid Diagnostic Tests in Formal Private Health Facilities in Nigeria. Malaria Journal, 15, 4. http://www.ncbi.nlm.nih.gov/pubmed/26728037 https://doi.org/10.1186/s12936-015-1064-x

[14] Mubi, M., Kakoko, D., Ngasala, B., Premji, Z., Peterson, S., Björkman, A., et al. (2013) Malaria Diagnosis and Treatment Practices Following Introduction of Rapid Diagnostic Tests in Kibaha District, Coast Region, Tanzania. Malaria Journal, 12, Article No. 293.

http://malariajournal.biomedcentral.com/articles/10.1186/1475-2875-12-293 https://doi.org/10.1186/1475-2875-12-293

[15] Hamer, D.H., Ndhlovu, M., Zurovac, D., Fox, M., Yeboah-Antwi, K., Chanda, P., et al. (2007) Improved Diagnostic Testing and Malaria Treatment Practices in Zambia. $J A M A, 297,2227-2231$. https://doi.org/10.1001/jama.297.20.2227

[16] Kabaghe, A.N., Visser, B.J., Spijker, R., Phiri, K.S., Grobusch, M.P. and van Vugt, M. (2016) Health Workers' Compliance to Rapid Diagnostic Tests (RDTs) to Guide Malaria Treatment: A Systematic Review and Meta-Analysis. Malaria Journal, 15, 163.

http://www.ncbi.nlm.nih.gov/entrez/query.fcgi?cmd=Retrieve\&db=PubMed\&dopt= Citation\&list_uids $=26979286$ https://doi.org/10.1186/s12936-016-1218-5

[17] Grover-Kopec, E.K., Blumenthal, M.B., Ceccato, P., Dinku, T., Omumbo, J.A. and Connor, S.J. (2006) Web-Based Climate Information Resources for Malaria Control in Africa. Malaria Journal, 5, Article No. 38.

http://malariajournal.biomedcentral.com/articles/10.1186/1475-2875-5-38 https://doi.org/10.1186/1475-2875-5-38

[18] Charan, J. and Biswas, T. (2013) How to Calculate Sample Size for Different Study Designs in Medical Research? Indian Journal of Psychological Medicine, 35, 121-126. http://www.ijpm.info/text.asp?2013/35/2/121/116232 https://doi.org/10.4103/0253-7176.116232

[19] Chanda, P., Hamainza, B., Moonga, H.B., Chalwe, V. and Pagnoni, F. (2011) Community Case Management of Malaria Using ACT and RDT in Two Districts in Zambia: Achieving High Adherence to Test Results Using Community Health Workers. Malaria Journal, 10, Article No. 158.

http://malariajournal.biomedcentral.com/articles/10.1186/1475-2875-10-158 https://doi.org/10.1186/1475-2875-10-158

[20] Burchett, H.E.D., Leurent, B., Baiden, F., Baltzell, K., Björkman, A., Bruxvoort, K., et al. (2017) Improving Prescribing Practices with Rapid Diagnostic Tests (RDTs), Synthesis of 10 Studies to Explore Reasons for Variation in Malaria RDT Uptake and Adherence. BMJ Open, 7, e012973. https://doi.org/10.1136/bmjopen-2016-012973

[21] Chanda, P., Hamainza, B., Moonga, H.B., Chalwe, V. and Pagnoni, F. (2011) Community Case Management of Malaria Using ACT and RDT in Two Districts in Zambia: Achieving High Adherence to Test Results Using Community Health 
Workers. Malaria Journal, 10, 158. https://doi.org/10.1186/1475-2875-10-158

[22] Bamiselu, O.F., Ajayi, I., Fawole, O., Dairo, D., Ajumobi, O., Oladimeji, A., et al. (2016) Adherence to Malaria Diagnosis and Treatment Guidelines among Healthcare Workers in Ogun State, Nigeria. BMC Public Health, 16, Article No. 828. http://bmcpublichealth.biomedcentral.com/articles/10.1186/s12889-016-3495-x https://doi.org/10.1186/s12889-016-3495-x

[23] Mbacham, W.F., Mangham-Jefferies, L., Cundill, B., Achonduh, O.A., Chandler, C.I.R., Ambebila, J.N., et al. (2014) Basic or Enhanced Clinician Training to Improve Adherence to Malaria Treatment Guidelines: A Cluster-Randomised Trial in Two Areas of Cameroon. The Lancet Global Health, 2, e346-e358. https://doi.org/10.1016/S2214-109X(14)70201-3

[24] Cundill, B., Mbakilwa, H., Chandler, C.I.R., Mtove, G., Mtei, F., Willetts, A., et al. (2015) Prescriber and Patient-Oriented Behavioural Interventions to Improve Use of Malaria Rapid Diagnostic Tests in Tanzania: Facility-Based Cluster Randomised Trial. BMC Medicine, 13, 118. https://doi.org/10.1186/s12916-015-0346-Z

[25] Bisoffi, Z., Sirima, B.S., Angheben, A., Lodesani, C., Gobbi, F., Tinto, H., et al. (2009) Rapid Malaria Diagnostic Tests vs. Clinical Management of Malaria in Rural Burkina Faso: Safety and Effect on Clinical Decisions. A Randomized Trial. Tropical Medicine \& International Health, 14, 491-498. https://doi.org/10.1111/j.1365-3156.2009.02246.x

[26] Kyabayinze, D.J., Asiimwe, C., Nakanjako, D., Nabakooza, J., Bajabaite, M., Strachan, C., et al. (2012) Programme Level Implementation of Malaria Rapid Diagnostic Tests (RDTs) Use: Outcomes and Cost of Training Health Workers at Lower Level Health Care Facilities in Uganda. BMC Public Health, 12, 291. https://doi.org/10.1186/1471-2458-12-291

[27] McMorrow, M.L., Aidoo, M. and Kachur, S.P. (2011) Malaria Rapid Diagnostic Tests in Elimination Settings-Can They Find the Last Parasite? Clinical Microbiology and Infection, 17, 1624-1631. https://doi.org/10.1111/j.1469-0691.2011.03639.x

[28] Davis, K.M., Gibson, L.E., Haselton, F.R. and Wright, D.W. (2014) Simple Sample Processing Enhances Malaria Rapid Diagnostic Test Performance. Analyst, 139, 3026-3031. http://pubs.rsc.org/en/content/articlehtml/2014/an/c4an00338a https://doi.org/10.1039/C4AN00338A

[29] Selemani, M., Masanja, I.M., Kajungu, D., Amuri, M., Njozi, M. and Khatib, R.A. (2013) Health Worker Factors Associated with Prescribing of Artemisinin Combination Therapy for Uncomplicated Malaria in Rural Tanzania. Malaria Journal, 12, 334. https://doi.org/10.1186/1475-2875-12-334

[30] Bottieau, E. (2013) Point-of-Care Testing: Filling the Diagnostic Gaps in Tropical Medicine? Clinical Microbiology and Infection, 19, 397-398.

https://doi.org/10.1111/1469-0691.12200

[31] Chinkhumba, J., Skarbinski, J., Chilima, B., Campbell, C., Ewing, V., San Joaquin, M., et al. (2010) Comparative Field Performance and Adherence to Test Results of Four Malaria Rapid Diagnostic Tests among Febrile Patients More than Five Years of Age in Blantyre, Malawi. Malaria Journal, 9, 209. https://doi.org/10.1186/1475-2875-9-209

[32] Shakely, D., Elfving, K., Aydin-Schmidt, B., Msellem, M.I., Morris, U., Omar, R., et al. (2013) The Usefulness of Rapid Diagnostic Tests in the New Context of Low Malaria Transmission in Zanzibar. PLoS ONE, 8, e72912. http://dx.plos.org/10.1371/journal.pone.0072912 https://doi.org/10.1371/journal.pone.0072912 


\section{Abbreviations}

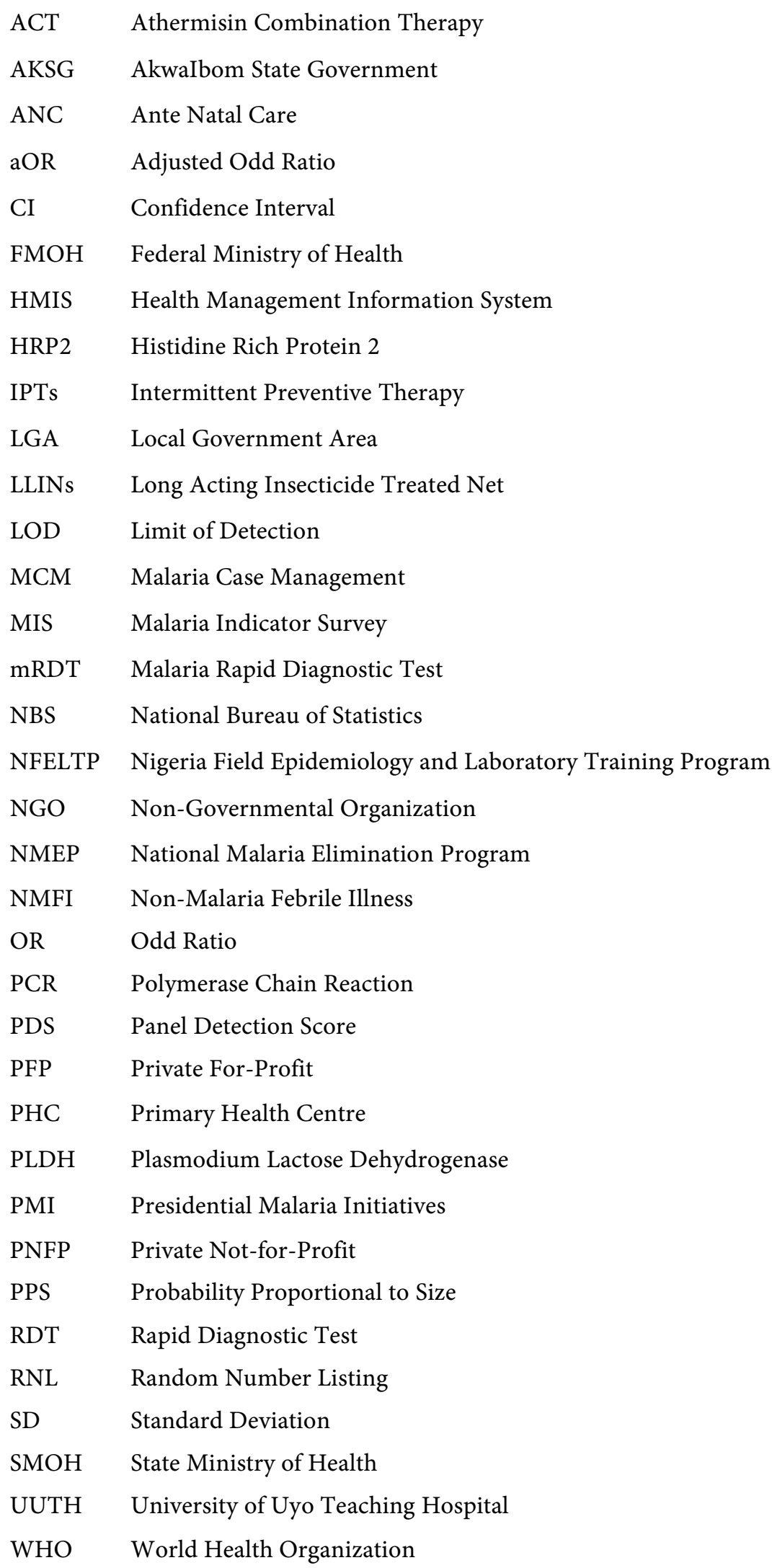


G. B. Effah et al.

\section{Appendix}

Form A: Data abstraction sheet

Facility

Unique identifier of clinician (respondent)

\begin{tabular}{|c|c|c|c|c|c|c|c|c|c|}
\hline $\mathrm{S} / \mathrm{N}$ & $\begin{array}{l}\text { Patient ID. } \\
\text { NO. }\end{array}$ & Age & Sex & Date & $\begin{array}{c}\text { OPD attendance } \\
\text { corresponding to } \\
\text { case }\end{array}$ & Temperature & RDT requested & RDT result & $\begin{array}{c}\text { Anti-malarial } \\
\text { prescribed }\end{array}$ \\
\hline
\end{tabular}

